\title{
Impact of Underlying Comorbidities on Outcomes of Patients Treated with Ceftaroline Fosamil for Complicated Skin and Soft Tissue Infections: Pooled Results from Three Phase III Randomized Clinical Trials
}

\author{
Mark Wilcox (D) · Jean Li Yan · Pedro L. Gonzalez • Matthew Dryden • \\ Gregory G. Stone $\cdot$ Michal Kantecki
}

Received: September 6, 2021 / Accepted: October 21, 2021 / Published online: November 6, 2021

(C) The Author(s) 2021

\section{ABSTRACT}

Introduction: In three phase III randomized controlled trials, ceftaroline fosamil was shown to be non-inferior to vancomycin plus aztreonam for the treatment of complicated skin and soft tissue infections (cSSTIs). This exploratory analysis evaluated the impact of underlying comorbidities on clinical outcomes in patients with cSSTI pooled from these three studies.

Methods: CANVAS 1 and 2 and COVERS evaluated ceftaroline fosamil (600 mg every $12 \mathrm{~h}$ [q12h]; $600 \mathrm{mg}$ every $8 \mathrm{~h}$ [q8h; COVERS]) versus

Supplementary Information The online version contains supplementary material available at https:// doi.org/10.1007/s40121-021-00557-w.

M. Wilcox $(\square)$

Department of Microbiology, Leeds Teaching

Hospitals, University of Leeds, Leeds LS1 3EX, UK

e-mail: mark.wilcox@nhs.net

J. L. Yan

Pfizer, New York, NY, USA

P. L. Gonzalez

AbbVie, Madison, NJ, USA

M. Dryden

Royal Hampshire County Hospital, Winchester, UK

G. G. Stone

Pfizer, Groton, CT, USA

M. Kantecki

Pfizer, Paris, France vancomycin plus aztreonam $(1 \mathrm{~g}$ q12h each [CANVAS 1 and 2]; vancomycin $15 \mathrm{mg} / \mathrm{kg}$ q12h and aztreonam $1 \mathrm{~g}$ q8h [COVERS]) in hospitalized adults with cSSTI. The primary efficacy variable in each trial was clinical response at the test-of-cure (TOC) visit. Subgroup analyses were performed on the pooled clinically evaluable (CE) population, exploring the impact of age and various baseline comorbidities.

Results: Overall, 1808 patients were included in the CE population (1005 ceftaroline fosamil; 803 vancomycin plus aztreonam). Clinical cure rates at TOC were $89.7 \%$ (ceftaroline fosamil) and $90.8 \%$ (vancomycin plus aztreonam) (difference $[95 \%$ confidence interval $]-1.13$ $[-3.87,1.67])$. Clinical response rates were similar between treatment groups, regardless of age ( $\leq 65$ years or $>65$ years), and in subgroups of patients with and without diabetes mellitus, peripheral vascular disease, cancer/malignancy, renal impairment, and obesity; within these subgroups, efficacy and safety results were generally consistent with those of the overall cSSTI population.

Conclusions: This analysis provides supportive evidence of the efficacy of ceftaroline fosamil in patients with cSSTI and underlying comorbidities.

Trial Registration: CANVAS 1, NCT00424190 and CANVAS 2, NCT00423657 (both trials first posted on ClinicalTrials.gov 18/01/2007); COVERS, NCT01499277 (first posted on ClinicalTrials.gov 26/12/2011). 
Keywords: Ceftaroline fosamil; Complicated skin and soft tissue infection; Comorbidities

\section{Key Summary Points}

Why carry out this study?

Patients with complicated skin and soft tissue infections (cSSTIs) frequently have underlying comorbidities, which may complicate or delay treatment response, leading to increased risks of treatment failure and mortality

This exploratory analysis evaluated the impact of underlying comorbidities on clinical outcomes in patients with cSSTI treated with ceftaroline fosamil or vancomycin plus aztreonam pooled from three phase III randomized, controlled studies

\section{What was learned from the study?}

Overall clinical and microbiological response rates were similar for ceftaroline fosamil and vancomycin plus aztreonam and were generally similar between treatment groups regardless of age or comorbidity status

The pattern of adverse events within each comorbidity subgroup was similar between treatment groups

This pooled analysis provides supportive evidence of the efficacy of ceftaroline fosamil in patients with cSSTI with underlying comorbidities

\section{INTRODUCTION}

Complicated skin and soft tissue infections (cSSTIs), also known as acute bacterial skin and skin structure infections (ABSSSIs), are among the most common infections encountered in the healthcare setting $[1,2]$. Patients with cSSTI frequently have underlying comorbidities $[3,4]$.
The presence of underlying comorbidities may complicate or delay treatment response in patients with cSSTI, leading to increased risks of treatment failure and mortality [1, 4-6]. Consequently, patients with comorbidities have been shown to require significantly greater use of healthcare resources, such as increased time to clinical stability and longer hospital stay [4], thus adding to the healthcare burden already associated with cSSTI.

Management of cSSTI/ABSSSI typically includes surgical debridement/draining and antibiotic therapy. Antimicrobial treatment options for cSSTI/ABSSSI cases involving possible/confirmed methicillin-resistant Staphylococcus aureus (MRSA) include vancomycin, linezolid, ceftaroline fosamil, and daptomycin $[2,7]$.

In the pivotal phase III CANVAS 1 and 2 studies, ceftaroline fosamil $600 \mathrm{mg}$ every $12 \mathrm{~h}$ (q12h) by 1-h intravenous (IV) infusions (doses adjusted for patients with moderate or severe renal impairment) was shown to be non-inferior to vancomycin plus aztreonam in hospitalized adults with cSSTI $[1,8]$. In a further phase III randomized controlled study (COVERS), a 50\% higher dose of ceftaroline fosamil (600 mg every $8 \mathrm{~h}$ [q8h] by 2-h IV infusions, again adjusted for renal function) was shown to be non-inferior to vancomycin plus aztreonam in patients with cSSTI with extensive cutaneous involvement, including evidence of systemic inflammation or underlying comorbidities associated with impaired immune response [9].

A previous pharmacokinetic study in healthy volunteers found, as expected, ceftaroline fosamil q8h dosing to result in increased drug exposure and higher pharmacokinetic/pharmacodynamic target attainment rates versus $\mathrm{q} 12 \mathrm{~h}$ dosing, particularly with minimum inhibitory concentrations $>1 \mathrm{mg} / \mathrm{l}$; however, high interindividual variability in relevant pharmacokinetic parameters was observed. The clinical implications of these findings were considered limited, with q12h dosing deemed likely sufficient for the treatment of infections caused by the vast majority of pathogens [10]. Although the CANVAS 1 and 2 and COVERS studies differed with respect to ceftaroline fosamil doses, as well as with respect to patients' overall 
disease severity and extent of comorbidities, a comparative subgroup analysis demonstrated generally equivalent outcomes for ceftaroline fosamil q12h and q8h when patients with similar comorbidities and/or disease severity were compared [11]. In conjunction with the similar study designs, this finding supports pooling of the CANVAS and COVERS data for further analysis.

The current exploratory analysis evaluated the impact of underlying comorbidities on clinical outcomes in patients with cSSTI pooled from the CANVAS 1, CANVAS 2, and COVERS studies.

\section{METHODS}

\section{Study Design and Patient Population}

The CANVAS 1 (NCT00424190), CANVAS 2 (NCT00423657), and COVERS (NCT01499277) studies were all phase III, multicenter, randomized, double-blind, comparative safety and efficacy trials of IV ceftaroline fosamil vs. vancomycin plus aztreonam for the treatment of adults with cSSTI (Table S1 in the Supplementary Material). Ethics approval of the study protocols and any amendments from the relevant IRB/IECs, and written informed consent, were obtained for each trial $[1,8,9]$, and all trials were conducted in accordance with the Helsinki Declaration of 1964, and its later amendments.

Full details of the methods used in each of the studies have been previously described $[1,8,9]$. In brief, CANVAS 1 and 2 included patients with cSSTI (defined as deep extensive cellulitis, major cutaneous abscess needing surgical drainage, or infected wound, ulcer, or burn) requiring hospitalization and $\geq 5$ days of parenteral antibiotic therapy. Inclusion criteria for COVERS were similar to the CANVAS studies, but in addition required cSSTI with surrounding area of erythema, edema, and/or induration with a surface area $\geq 75 \mathrm{~cm}^{2}$, and patients had to have one or more sign/symptom of systemic inflammation or comorbidities. In COVERS, patients with diabetic foot infections were excluded. Full eligibility criteria for each of the studies are provided in the Supplementary Material.

In each of the three studies, patients were randomized to receive ceftaroline fosamil or vancomycin plus aztreonam for 5-14 days. Randomization and blinding information is provided in the Supplementary Material. Details of the treatment regimens and the numbers of patients included in the studies are provided in Table S1 in the Supplementary Material. An overview of study design is shown in Fig. S1 in the Supplementary Material.

\section{Assessments}

In each study, the primary endpoint was clinical cure at the test-of-cure (TOC) visit (8-15 days after last dose of study drug), in the modified intention-to-treat (MITT) and clinically evaluable (CE) populations. Per-pathogen microbiological response rates were assessed at TOC for the microbiological MITT (mMITT) population. Safety assessments included adverse event (AE) monitoring, vital signs, physical examinations, and clinical chemistry/laboratory tests up to the late follow-up visit (21-35 days after the last dose of study drug) in the safety population. Definitions of analysis populations are provided in the Supplementary Material.

\section{Statistical Analysis}

Statistical methods for the key primary and secondary endpoints and safety assessments, including sample size calculations and non-inferiority, have been reported previously $[1,8,9]$.

Exploratory subgroup analyses assessing the impact of baseline characteristics and comorbidities on clinical outcomes at TOC were performed for the pooled CE population. Subgroups were defined programmatically from patients' baseline information and medical history as recorded in the study case report forms and included age group ( $\leq 65$ years or $>65$ years) and presence/absence of diabetes mellitus, peripheral vascular disease (PVD), cancer/malignancy, renal impairment (mild impairment/normal renal function: estimated creatinine clearance $\left[\mathrm{CL}_{\mathrm{CR}}\right]>50 \mathrm{ml} / \mathrm{min}$; 
moderate impairment: $\mathrm{CL}_{\mathrm{CR}}>30$ to $\leq 50 \mathrm{ml} /$ min; severe impairment: $\mathrm{CL}_{\mathrm{CR}}>20$ to $\leq 30 \mathrm{ml} /$ min), and body mass index (BMI; $<18.5 \mathrm{~kg} /$ $\mathrm{m}^{2}$, $\geq 18.5$ to $<25 \mathrm{~kg} / \mathrm{m}^{2}$, $\geq 25$ to $<30 \mathrm{~kg} / \mathrm{m}^{2}$, and $\geq 30 \mathrm{~kg} / \mathrm{m}^{2}$ ).

The 95\% CIs for the observed difference in the outcome measure between the ceftaroline fosamil and vancomycin plus aztreonam groups were calculated using the method of Miettinen and Nurminen [12].

\section{RESULTS}

\section{Patient Characteristics and Baseline Pathogens}

Patient disposition is shown in Fig. S2 in the Supplementary Material. The pooled MITT population included 2139 patients (ceftaroline fosamil, $n=1199$; vancomycin plus aztreonam, $n=940$ [difference in numbers between the two groups is a result of the 2:1 ceftaroline fosamil: vancomycin plus aztreonam randomization ratio in the COVERS study]). One patient in the CANVAS 2 study who was randomized to receive ceftaroline fosamil was given vancomycin plus aztreonam in error. Per protocol, this patient was grouped according to actual treatment received in the safety population, which thus comprised 2139 patients (ceftaroline fosamil, $n=1198$; vancomycin plus aztreonam, $n=941$ ). The pooled CE population included 1808 patients (ceftaroline fosamil, $n=1005$; vancomycin plus aztreonam, $n=803$ ). Baseline and demographic characteristics were generally similar between treatment arms (Table 1).

The most frequently isolated pathogens at baseline (infection site and blood) were methicillin-sensitive S. aureus (MSSA; 352/787 [44.7\%] and 319 [48.4\%] for ceftaroline fosamil and vancomycin plus aztreonam, respectively), MRSA (210/787 [26.7\%] and 174 [26.4\%], respectively), and Streptococcus pyogenes (81/787 [10.3\%] and 69/659 [10.5\%], respectively). In vitro activity of the most common baseline pathogens (isolated from $\geq 10$ patients in either treatment group) to ceftaroline fosamil and vancomycin or aztreonam is summarized in Table 2.

\section{Clinical Outcomes}

Overall clinical cure rates at TOC (CE population) were similar for ceftaroline fosamil $(n=901 / 1005$ [89.7\%]) and for vancomycin plus aztreonam $(n=729 / 803$ [90.8\%]); difference $(95 \% \mathrm{CI})-1.13 \%(-3.87,1.67)$. Clinical cure rates at TOC were similar for ceftaroline fosamil and vancomycin plus aztreonam, regardless of age or comorbidity status (Fig. 1). However, in patients with cancer/malignancy, clinical cure rates were $88.9 \%(n=24 / 27)$ for ceftaroline fosamil vs. $78.9 \% \quad(n=15 / 19)$ for vancomycin plus aztreonam (difference [95\% CI] $9.94 \%$ [- 11.66, 34.31]). In patients without cancer/malignancy, cure rates were $89.7 \%$ $(n=877 / 978)$ vs. $91.1 \%(n=714 / 784)$, respectively (treatment difference [95\% CI] $-1.40 \%$ $[-4.15,1.41])$.

In patients with moderate renal impairment, clinical cure rates were $84.8 \%(n=39 / 46)$ for ceftaroline fosamil vs. $78.4 \%(n=29 / 37)$ for vancomycin plus aztreonam (difference [95\% CI]: 6.40\% [-10.43, 24.29]) (Fig. 1).

In patients with $\mathrm{BMI}<18.5 \mathrm{~kg} / \mathrm{m}^{2}$, clinical cure rates were $69.2 \%(n=18 / 26)$ for ceftaroline fosamil vs. $90.9 \%$ for vancomycin plus aztreonam $\quad(n=10 / 11) \quad$ (difference $[95 \% \quad \mathrm{CI}]$ $-21.68 \%$ [- 44.09, 10.98]). Respective clinical cure rates for $\mathrm{BMI} \geq 18.5$ to $<25 \mathrm{~kg} / \mathrm{m}^{2}$ were $91.0 \% \quad(n=312 / 343)$ vs. $89.9 \% \quad(n=232 / 258)$ (difference [95\% CI] $1.04[-3.66,6.06])$, for $\mathrm{BMI} \geq 25$ to $<30 \mathrm{~kg} / \mathrm{m}^{2} \quad 90.9 \% \quad(n=288 / 317)$ vs. $93.6 \%(n=263 / 281)$ (difference $[95 \% \mathrm{CI}]$ $-2.74[-7.14,1.66])$, and for BMI $\geq 30 \mathrm{~kg} / \mathrm{m}^{2}$ $89.2 \%(n=281 / 315)$ vs. $88.5 \%(n=223 / 252)$ (difference [95\% CI] 0.71 [- 4.47, 6.15]) (Fig. 1).

Overall favorable microbiological response rates for the most commonly isolated pathogens at TOC (mMITT population) were similar for ceftaroline fosamil and vancomycin plus aztreonam (MSSA: 318/352 [90.3\%] and 283/319 [88.7\%], respectively; MRSA: 178/210 [84.8\%] and 135/174 [77.6\%], respectively; and S. pyogenes: 72/81 [88.9\%] and 64/69 [92.8\%], respectively). Favorable microbiological 
Table 1 Baseline demographic characteristics and comorbidities (CE population)

Number (\%) of patients

\begin{tabular}{lll}
\hline $\begin{array}{l}\text { Ceftaroline fosamil } \\
(n=1005)\end{array}$ & $\begin{array}{l}\text { Vancomycin }+ \text { aztreonam } \\
(n=803)\end{array}$ & $\begin{array}{l}\text { Total } \\
(N=1808)\end{array}$
\end{tabular}

Demographic characteristic

Age (years)

Mean $\quad 49.7$

Median (range)

$16.9(18-93)$

$805(80.1)$

$112(11.1)$

$88(8.8)$

$\geq 75$

Age group (years), $n$ (\%)

$\geq 18$ to $<65$

$\geq 65$ to $<75$

Sex, $n(\%)$

Female

$372(37.0)$

Comorbidity/analysis subgroup, $n$ (\%)

Age $>65$ years

$188(18.7)$

$173(17.2)$

$113(11.2)$

Peripheral vascular disease

$27(2.7)$

Cancer/malignancy $(n=803)$

$(N=1808)$

Renal status (estimated $\left.\mathrm{CL}_{\mathrm{CR}}, \mathrm{ml} / \mathrm{min}\right)^{\mathrm{a}}$

$\begin{array}{llcc}\begin{array}{l}\text { Severe impairment }(>20 \\ \text { to } \leq 30)\end{array} & 4(0.4) & 1(0.1) & 5(0.3) \\ \begin{array}{l}\text { Moderate impairment }(>30 \\ \text { to } \leq 50)\end{array} & 46(4.6) & 37(4.6) & 83(4.6) \\ \begin{array}{l}\text { Mild impairment or normal } \\ (>50)\end{array} & 946(94.1) & 759(94.5) & 1705(94.3)\end{array}$

Body mass index $\left(\mathrm{kg} / \mathrm{m}^{2}\right)^{\mathrm{b}}$
$<18.5$
$26(2.6)$
$11(1.4)$
$37(2.0)$
$\geq 18.5$ to $<25$
$343(34.1)$
$258(32.1)$
$601(33.2)$
$\geq 25$ to $<30$
317 (31.5)
$281(35.0)$
$598(33.1)$
$\geq 30$
315 (31.3)
$252(31.4)$
$567(31.4)$

$C E$ clinically evaluable, $C L_{C R}$ creatinine clearance

${ }^{a}$ Data not collected for nine patients in the ceftaroline group and six patients in the vancomycin plus aztreonam group

${ }^{b}$ Data not collected for four patients in the ceftaroline group and one patient in the vancomycin plus aztreonam group 
Table 2 In vitro activity of ceftaroline, vancomycin, and aztreonam against pathogens isolated from patients with cSSTI (mMITT population)

\begin{tabular}{|c|c|c|c|c|c|c|c|c|c|}
\hline \multirow[t]{2}{*}{ Baseline pathogen } & \multicolumn{3}{|c|}{ Ceftaroline $(N=787)$} & \multicolumn{3}{|c|}{ Vancomycin $(N=659)$} & \multicolumn{3}{|c|}{ Aztreonam $(N=659)$} \\
\hline & $\begin{array}{l}\text { Isolates } \\
(n)\end{array}$ & $\begin{array}{l}\text { MIC } \\
\text { range }\end{array}$ & $\mathrm{MIC}_{90}$ & $\begin{array}{l}\text { Isolates } \\
(n)\end{array}$ & $\begin{array}{l}\text { MIC } \\
\text { range }\end{array}$ & $\overline{\mathrm{MIC}_{90}}$ & $\begin{array}{l}\text { Isolates } \\
(n)\end{array}$ & $\begin{array}{l}\text { MIC } \\
\text { range }\end{array}$ & $\overline{\mathrm{MIC}_{90}}$ \\
\hline \multicolumn{10}{|l|}{ Gram-positive organisms } \\
\hline Staphylococcus aureus & 535 & 0.06 to 2 & 0.5 & 461 & $\begin{array}{l}\leq 0.25 \\
\text { to } 2\end{array}$ & 1 & - & - & - \\
\hline$M S S A$ & 105 & $\begin{array}{c}0.06 \text { to } \\
0.5\end{array}$ & 0.25 & 59 & $\begin{array}{l}\leq 0.25 \\
\text { to } 1\end{array}$ & 1 & - & - & - \\
\hline$M R S A$ & 32 & 0.25 to 1 & 1 & 22 & 0.5 to 1 & 1 & - & - & - \\
\hline Streptococcus pyogenes & 80 & $\begin{array}{l}\leq 0.004 \\
\text { to } \\
0.008\end{array}$ & $\leq 0.008$ & 68 & $\begin{array}{l}\leq 0.25 \\
\text { to } 1\end{array}$ & 0.5 & - & - & - \\
\hline $\begin{array}{r}\text { Streptococcus } \\
\text { dysgalactiae }\end{array}$ & 13 & $\begin{array}{l}\leq 0.004 \\
\text { to } \\
0.008\end{array}$ & 0.008 & 17 & $\begin{array}{c}0.25 \text { to } \\
0.5\end{array}$ & 0.25 & - & - & - \\
\hline Enterococcus faecalis & 41 & 0.25 to 64 & 8 & 33 & 0.5 to 2 & 2 & - & - & - \\
\hline $\begin{array}{l}\text { Streptococcus } \\
\text { agalactiae }\end{array}$ & 30 & $\begin{array}{l}\leq 0.008 \\
\text { to } \\
0.015\end{array}$ & 0.015 & 29 & $\begin{array}{r}\leq 0.25 \\
\text { to } 0.5\end{array}$ & 0.5 & - & - & - \\
\hline $\begin{array}{l}\text { Streptococcus anginosus } \\
\text { group }\end{array}$ & 24 & $\begin{array}{l}\leq 0.004 \\
\text { to } \\
0.008\end{array}$ & 0.03 & 3 & $\begin{array}{c}0.5 \text { to } \\
0.5\end{array}$ & 0.5 & - & - & - \\
\hline $\begin{array}{l}\text { Streptococcus } \\
\text { dysgalactiae subspecies } \\
\text { dysgalactiae }\end{array}$ & 11 & $\begin{array}{l}\leq 0.008 \\
\text { to } \\
0.015\end{array}$ & 0.015 & 1 & 1 to 1 & 1 & - & - & - \\
\hline Finegoldia magna & 13 & $\begin{array}{r}\leq 0.06 \\
\text { to } 64\end{array}$ & 0.5 & 1 & $\begin{array}{c}0.25 \text { to } \\
0.25\end{array}$ & 0.25 & 1 & 32 to 32 & 32 \\
\hline \multicolumn{10}{|l|}{ Gram-negative organisms } \\
\hline Escherichia coli & 42 & $\begin{array}{l}0.015 \\
\quad \text { to }>32\end{array}$ & 16 & - & - & - & 31 & $\begin{array}{r}\leq 0.03 \\
\text { to } 0.5\end{array}$ & 0.12 \\
\hline $\begin{array}{l}\text { Acinetobacter } \\
\text { calcoaceticus }\end{array}$ & 10 & 2 to $>32$ & $>32$ & - & - & - & 5 & 1 to $>32$ & $>32$ \\
\hline Klebsiella pneumoniae & 26 & $\begin{array}{l}0.03 \\
\text { to }>32\end{array}$ & $>16$ & - & - & - & 23 & $\begin{array}{l}\leq 0.03 \\
\text { to }>32\end{array}$ & $>32$ \\
\hline Klebsiella oxytoca & 18 & $\begin{array}{c}0.03 \text { to } \\
0.25\end{array}$ & 0.25 & - & - & - & 9 & $\begin{array}{r}\leq 0.03 \\
\text { to } 0.5\end{array}$ & 0.5 \\
\hline
\end{tabular}


Table 2 continued

\begin{tabular}{|c|c|c|c|c|c|c|c|c|c|}
\hline \multirow[t]{2}{*}{ Baseline pathogen } & \multicolumn{3}{|c|}{ Ceftaroline $(N=787)$} & \multicolumn{3}{|c|}{ Vancomycin $(N=659)$} & \multicolumn{3}{|c|}{ Aztreonam $(N=659)$} \\
\hline & $\begin{array}{l}\text { Isolates } \\
(n)\end{array}$ & $\begin{array}{l}\text { MIC } \\
\text { range }\end{array}$ & $\mathrm{MIC}_{90}$ & $\begin{array}{l}\text { Isolates } \\
(n)\end{array}$ & $\begin{array}{l}\text { MIC } \\
\text { range }\end{array}$ & $\mathrm{MIC}_{90}$ & $\begin{array}{l}\text { Isolates } \\
(n)\end{array}$ & $\begin{array}{l}\text { MIC } \\
\text { range }\end{array}$ & $\mathrm{MIC}_{90}$ \\
\hline Proteus mirabilis & 23 & $\begin{array}{l}\leq 0.008 \\
\text { to }>16\end{array}$ & $>16$ & - & - & - & 27 & $\begin{array}{r}\leq 0.03 \\
\text { to } 16\end{array}$ & 0.25 \\
\hline Enterobacter cloacae & 11 & 0.06 to 1 & 1 & - & - & - & 19 & $\begin{array}{l}\leq 0.03 \\
\text { to }>32\end{array}$ & 16 \\
\hline $\begin{array}{l}\text { Pseudomonas } \\
\text { aeruginosa }\end{array}$ & 32 & 1 to $>32$ & $>16$ & - & - & - & 26 & 1 to $>32$ & $>32$ \\
\hline Morganella morganii & 15 & $\begin{array}{l}0.03 \\
\quad \text { to }>16\end{array}$ & $>16$ & - & - & - & 10 & $\begin{array}{l}\leq 0.03 \\
\text { to } 4\end{array}$ & 4 \\
\hline
\end{tabular}

Includes pathogens isolated from $\geq 10$ patients in either treatment group. MIC range and $\mathrm{MIC}_{90}$ are in $\mathrm{mg} / \mathrm{l}$

The mMITT population consisted of patients in the MITT population who met the minimal disease criteria and had $\geq 1$ bacterial pathogen

cSSTI complicated skin and soft tissue infection, $M I C$ minimum inhibitory concentration, $M I C_{90}$ minimum inhibitory concentration required to inhibit the growth of $90 \%$ of organisms, $m M I T T$ microbiological modified intention to treat, MRSA methicillin-resistant Staphylococcus aureus, MSSA methicillin-sensitive Staphylococcus aureus, $n$ number of isolates, $N$ number of patients

response rates were generally consistent within and between age and comorbidity subgroups (Table 3). Given that in each of the individual studies microbiological outcomes were largely inferred from clinical outcomes, the results for ME population were generally similar to those of the mMITT population.

\section{Safety}

Mean (standard deviation [SD]) study duration of exposure (safety population) was 8.27 (3.3) days for ceftaroline fosamil and 8.31 (3.3) days for vancomycin plus aztreonam, and exposures were generally consistent within and between age comorbidity subgroups. AEs and serious AEs up to the late follow-up visit are summarized in Table 4. Overall, treatment-emergent AEs were reported in 541/1198 (45.2\%) patients treated with ceftaroline fosamil and 442/941 (47.0\%) patients treated with vancomycin plus aztreonam (Table 4). The most frequently reported AEs were nausea (occurring in 61/1198 [5.1\%] patients treated with ceftaroline fosamil and 46/941 [4.9\%] patients treated with vancomycin plus aztreonam) and pruritis (occurring in 24/1199 [2.0\%] and 61/940 [6.5\%] patients, respectively).

Results from evaluation of vital signs, physical examinations, and clinical chemistry/laboratory tests were generally similar between treatment groups and within age and comorbidity subgroups.

\section{DISCUSSION}

This exploratory analysis evaluated the impact of a range of comorbidities on clinical outcomes in patients with cSSTI pooled from three phase III randomized controlled studies. The high proportions of patients with comorbidities, such as diabetes mellitus, PVD, and obesity, are considered representative of patients typically seen in clinical practice $[3,4]$.

Overall clinical cure rates at TOC (CE population) were similar for ceftaroline fosamil monotherapy (89.7\%) and for vancomycin plus aztreonam combination therapy $(90.8 \%)$, and were similar regardless of comorbidity status, and consistent with results in the CE and MITT 


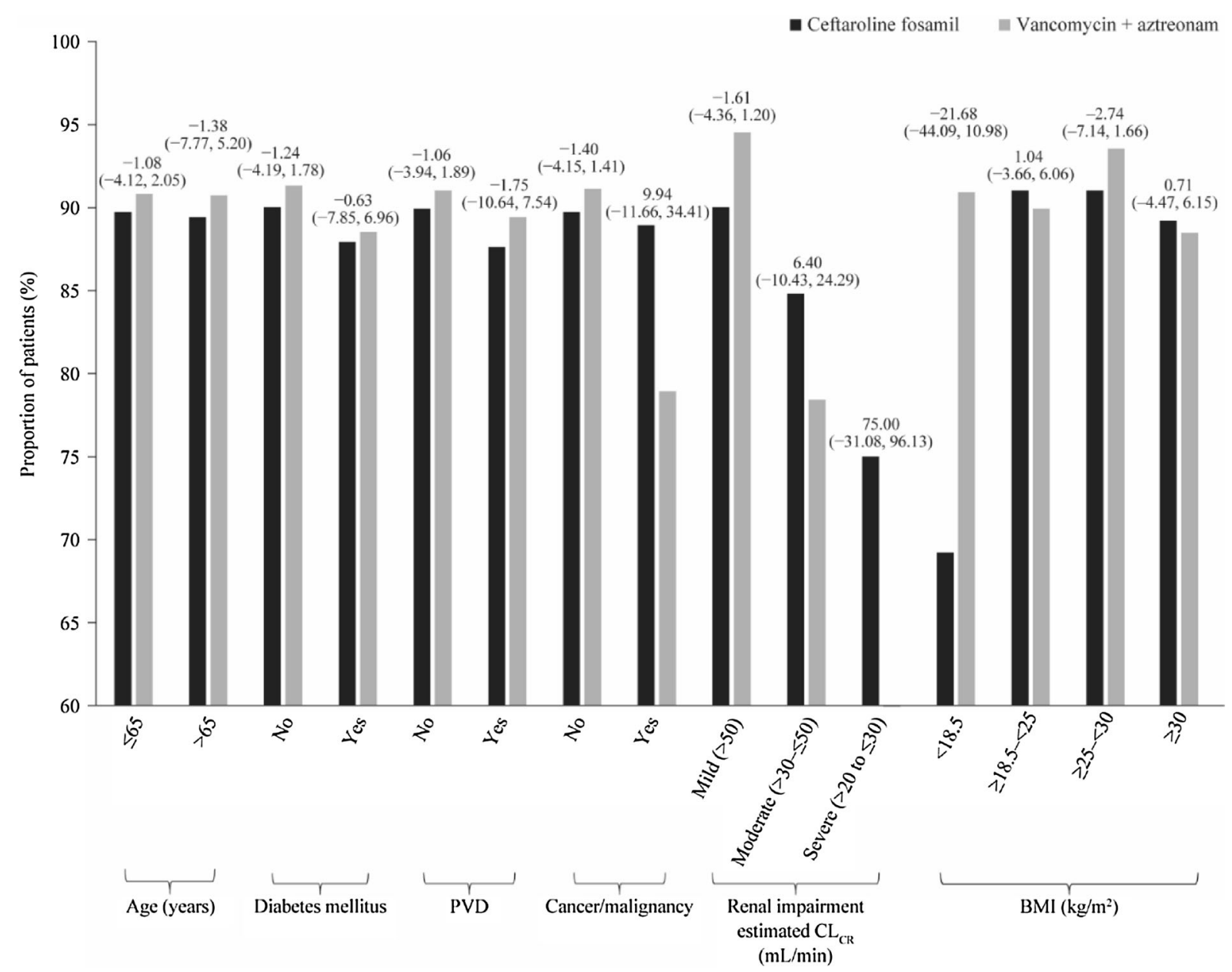

Fig. 1 Clinical cure rates at TOC by baseline age, BMI, and comorbidity subgroups in patients with cSSTI (CE population) $)^{a}$. $B M I$ body mass index, $C E$ clinically evaluable, $C L_{C R}$ creatinine clearance, $c S S T I$ complicated skin

populations in the individual trials $[1,8,9]$. Moreover, favorable microbiological response rates were generally comparable across comorbidity subtypes for key cSSTI pathogens, including $S$. aureus.

Presence of comorbidities may increase the likelihood of acquiring a cSSTI and have an impact on the progression and course of the condition as well as its response to treatment [5]. Comorbidities associated with impaired immune response include critical illness, elderly age, immunocompromised state, hepatic and renal disease, vascular insufficiency, and malignancy $[5,9,13,14]$. Such comorbidities and soft tissue infection, $P V D$ peripheral vascular disease,

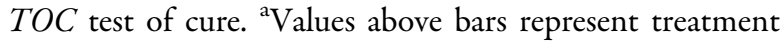
differences $(95 \% \mathrm{CI})$

represent risk factors for potentiation of CSSTI and poor wound healing. Moreover, severe systemic inflammation can affect antibiotic pharmacokinetics, potentially negatively affecting efficacy [15].

In patients with diabetes mellitus or PVD, the ability of some antibiotics to penetrate soft tissues may be compromised, resulting in a lower drug concentration reaching the site of infection. It has previously been hypothesized that poor soft tissue distribution of vancomycin in patients with diabetes mellitus has been responsible for treatment failure in some patients [16-18]. Clinical cure response rates at 
Table 3 Per-pathogen favorable microbiological response rates at TOC for the most commonly isolated pathogens overall, by baseline age, and comorbidity subgroups in patients with cSSTI (mMITT population)

\begin{tabular}{|c|c|c|c|}
\hline \multirow[t]{2}{*}{ Subgroup } & \multirow[t]{2}{*}{ Pathogen } & \multicolumn{2}{|c|}{ Patients, $n / N(\%)$} \\
\hline & & $\begin{array}{l}\text { Ceftaroline } \\
\text { fosamil } \\
(n=787)\end{array}$ & $\begin{array}{l}\text { Vancomycin + aztreonam } \\
(n=659)\end{array}$ \\
\hline \multirow[t]{3}{*}{ Age $\leq 65$ years } & MSSA & $261 / 292(89.4)$ & $222 / 253(87.7)$ \\
\hline & MRSA & $161 / 192(83.9)$ & $123 / 159(77.4)$ \\
\hline & S. pyogenes & $66 / 75(88.0)$ & $57 / 61(93.4)$ \\
\hline \multirow[t]{3}{*}{ Age $>65$ years } & MSSA & $57 / 60(95.0)$ & $61 / 66(92.4)$ \\
\hline & MRSA & $17 / 18(94.4)$ & $12 / 15(80.0)$ \\
\hline & S. pyogenes & $6 / 6(100)$ & $7 / 8(87.5)$ \\
\hline \multirow[t]{3}{*}{ Diabetes mellitus: no } & MSSA & $271 / 303(89.4)$ & $240 / 273(87.9)$ \\
\hline & MRSA & $164 / 193(85.0)$ & $124 / 158(78.5)$ \\
\hline & S. pyogenes & $67 / 76(88.2)$ & $62 / 66(93.9)$ \\
\hline \multirow[t]{3}{*}{ Diabetes mellitus: yes } & MSSA & $47 / 49(95.9)$ & $43 / 46(93.5)$ \\
\hline & MRSA & $14 / 17(82.4)$ & $11 / 16(68.8)$ \\
\hline & S. pyogenes & $5 / 5(100)$ & $2 / 3(66.7)$ \\
\hline \multirow{3}{*}{ Peripheral vascular disease: no } & MSSA & $271 / 303(89.4)$ & $240 / 273(87.9)$ \\
\hline & MRSA & $164 / 193(85.0)$ & $124 / 158(78.5)$ \\
\hline & S. pyogenes & $67 / 76(88.2)$ & $62 / 66(93.9)$ \\
\hline \multirow[t]{3}{*}{ Peripheral vascular disease: yes } & MSSA & $47 / 49(95.9)$ & $43 / 46(93.5)$ \\
\hline & MRSA & $14 / 17(82.4)$ & $11 / 16(68.8)$ \\
\hline & S. pyogenes & $5 / 5(100)$ & $2 / 3(66.7)$ \\
\hline \multirow[t]{3}{*}{ Cancer/malignancy: no } & MSSA & $308 / 342(90.1)$ & $279 / 315(88.6)$ \\
\hline & MRSA & $174 / 206(84.5)$ & $130 / 168(77.4)$ \\
\hline & S. pyogenes & $72 / 81(88.9)$ & $64 / 69(92.8)$ \\
\hline \multirow[t]{3}{*}{ Cancer/malignancy: yes } & MSSA & $10 / 10(100)$ & $4 / 4(100)$ \\
\hline & MRSA & $4 / 4(100)$ & $5 / 6(83.3)$ \\
\hline & S. pyogenes & 0 & 0 \\
\hline \multirow[t]{3}{*}{ Severe renal impairment $\left(\mathrm{CL}_{\mathrm{CR}}>20\right.$ to $\left.\leq 30 \mathrm{ml} / \mathrm{min}\right)$} & MSSA & 0 & 0 \\
\hline & MRSA & 0 & 0 \\
\hline & S. pyogenes & $0 / 1(0)$ & 0 \\
\hline \multirow[t]{3}{*}{ Moderate renal impairment $\left(\mathrm{CL}_{\mathrm{CR}}>30\right.$ to $\left.\leq 50 \mathrm{ml} / \mathrm{min}\right)$} & MSSA & $13 / 13(100)$ & $10 / 12(83.3)$ \\
\hline & MRSA & $4 / 5(80.0)$ & $4 / 6(66.7)$ \\
\hline & S. pyogenes & $3 / 3(100)$ & $2 / 2(100)$ \\
\hline
\end{tabular}


Table 3 continued

\begin{tabular}{|c|c|c|c|}
\hline \multirow[t]{2}{*}{ Subgroup } & \multirow[t]{2}{*}{ Pathogen } & \multicolumn{2}{|c|}{ Patients, $n / N(\%)$} \\
\hline & & $\begin{array}{l}\text { Ceftaroline } \\
\text { fosamil } \\
(n=787)\end{array}$ & $\begin{array}{l}\text { Vancomycin + aztreonam } \\
(n=659)\end{array}$ \\
\hline \multirow[t]{3}{*}{ Mild renal impairment or normal $\left(\mathrm{CL}_{\mathrm{CR}}>50 \mathrm{ml} / \mathrm{min}\right)$} & MSSA & $302 / 336(89.9)$ & $271 / 304(89.1)$ \\
\hline & MRSA & $173 / 203(85.2)$ & $129 / 165(78.2)$ \\
\hline & S. pyogenes & $68 / 77(88.3)$ & $62 / 67(92.5)$ \\
\hline \multirow[t]{3}{*}{$\mathrm{BMI}<18.5 \mathrm{~kg} / \mathrm{m}^{2}$} & MSSA & $11 / 13(84.6)$ & $2 / 3(66.7)$ \\
\hline & MRSA & $0 / 2(0)$ & $2 / 3(66.7)$ \\
\hline & S. pyogenes & $5 / 5(100)$ & $1 / 1(100)$ \\
\hline \multirow[t]{3}{*}{$\mathrm{BMI} \geq 18.5$ to $<25 \mathrm{~kg} / \mathrm{m}^{2}$} & MSSA & $131 / 146(89.7)$ & $199 / 116(85.3)$ \\
\hline & MRSA & $61 / 72(84.7)$ & $38 / 54(70.4)$ \\
\hline & S. pyogenes & $33 / 39(84.6)$ & $36 / 39(92.3)$ \\
\hline \multirow{3}{*}{$\mathrm{BMI} \geq 25$ to $<30 \mathrm{~kg} / \mathrm{m}^{2}$} & MSSA & $91 / 101(90.1)$ & $107 / 113(94.7)$ \\
\hline & MRSA & $54 / 61(88.5)$ & $49 / 58(84.5)$ \\
\hline & S. pyogenes & $24 / 26(92.3)$ & $18 / 19(94.7)$ \\
\hline \multirow[t]{3}{*}{$\mathrm{BMI} \geq 30 \mathrm{~kg} / \mathrm{m}^{2}$} & MSSA & $85 / 92(92.4)$ & $75 / 87(86.2)$ \\
\hline & MRSA & $62 / 73(84.9)$ & $46 / 59(78.0)$ \\
\hline & S. pyogenes & $10 / 11(90.9)$ & $9 / 10(90.0)$ \\
\hline
\end{tabular}

$B M I$ body mass index, $C L_{C R}$ creatinine clearance, $C S S T I$ complicated skin and soft tissue infection, mMITT microbiological modified intention to treat, MRSA methicillin-resistant Staphylococcus aureus, MSSA methicillin-sensitive Staphylococcus aureus, $S$. pyogenes Streptococcus pyogenes, TOC test of cure

TOC were similar for ceftaroline fosamil and vancomycin plus aztreonam in patients with and without diabetes mellitus and in those with and without PVD.

Renal impairment is associated with impairment of host defenses [19]. Furthermore, drug pharmacokinetics are often affected by impaired renal clearance [14]. Of the small proportions of patients with moderate renal impairment $\left(\mathrm{CL}_{\mathrm{CR}}>30\right.$ to $\left.\leq 50 \mathrm{ml} / \mathrm{min}\right)$, clinical cure rates for patients treated with ceftaroline fosamil were $84.8 \%(n=39 / 46)$ and for patients treated with vancomycin plus aztreonam were $78.4 \%(n=29 / 37)$.

Patients with malignancy are highly susceptible to infection [13], and both hematological and solid tumors have been shown to influence the cSSTI disease course [20]. Among patients with malignancy, 24 of 27 (88.9\%) patients treated with ceftaroline fosamil and 15 of 19 (78.9\%) patients treated with vancomycin plus aztreonam were cured, although the small patient numbers limit the interpretation of these results. Previous studies have suggested that patients with certain malignancies may require much higher dosages of vancomycin than those with no known with malignancy to achieve therapeutic drug plasma concentrations [21-23]. However, these studies, and other literature on treatment of infections in patients with malignancy, included patients with varying levels of neutropenia. As patients with 
Table 4 Overview of AEs (safety population)

\begin{tabular}{|c|c|c|}
\hline & \multicolumn{2}{|c|}{ Number (\%) of patients } \\
\hline & $\begin{array}{l}\text { Ceftaroline fosamil } \\
(n=1198)\end{array}$ & $\begin{array}{l}\text { Vancomycin + aztreonam } \\
(n=941)\end{array}$ \\
\hline \multicolumn{3}{|l|}{ AE category } \\
\hline Patients with $\geq 1 \mathrm{AE}$ & $541(45.2)$ & $442(47.0)$ \\
\hline Any AE related to study drug & $244(20.4)$ & $223(23.7)$ \\
\hline Any AE with outcome of death & $8(0.7)$ & $3(0.3)$ \\
\hline Any SAE & $56(4.7)$ & $41(4.4)$ \\
\hline Any AE leading to discontinuation of study drug & $53(4.4)$ & $44(4.7)$ \\
\hline Any AE of severe intensity & $40(3.3)$ & $37(3.9)$ \\
\hline
\end{tabular}

$A E$ adverse event, $S A E$ serious adverse event

neutropenia $\left(<500\right.$ neutrophils $\left./ \mathrm{mm}^{3}\right)$ were excluded from the CANVAS and COVERS trials, comparisons with results from the literature should be made with caution.

Obesity and low antibiotic dosage at discharge are associated with cSSTI onset and clinical failure at hospital discharge [24, 25]. In addition, higher BMI may result in lower relative doses of an antibiotic that are not adjusted for body weight [17], potentially leading to less optimal clinical outcomes [26, 27]. However, model-based predictions of multiple ceftaroline fosamil doses have indicated adequate target attainment achievement with time-dependent pharmacodynamics [28]. Currently, there is no evidence for worse clinical outcomes in obese vs. non-obese patients with cSSTI using standard doses of ceftaroline fosamil [28]. In the present analysis, favorable clinical response rates at TOC were similar for ceftaroline and vancomycin plus aztreonam in patients with and without obesity.

Regardless of comorbidity status, some patients with cSSTI initially require empirical antibiotic treatment providing polymicrobial coverage [29]. Ceftaroline fosamil has a broad spectrum of activity against clinically relevant gram-positive strains, including MRSA, as well as some gram-negative pathogens involved in cSSTI $[30,31]$. In the current pooled analysis, patients with comorbidities that put them at risk of treatment failure demonstrated similar success rates in the ceftaroline fosamil and the vancomycin plus aztreonam treatment groups, with response rates generally consistent with those of the overall cSSTI population of the individual studies.

The lack of stratification for comorbidity at randomization represents a limitation of this analysis. Another limitation is the low numbers of patients in the $\mathrm{BMI}<18.5 \mathrm{~kg} / \mathrm{m}^{2}$, moderate/severe renal impairment, and malignancy subgroups, which make it difficult to draw conclusions from these results. Additionally, information regarding stability of the comorbidity, which may potentially impact response to therapy, was not collected as part of the current analysis.

Ceftaroline fosamil has been shown to have a favorable safety profile [32]. Observations from the CANVAS studies indicated that when AEs did occur with ceftaroline fosamil they were generally of mild intensity $[1,8]$. No new safety signals were reported for ceftaroline fosamil in the CANVAS or COVERS studies $[1,8,9]$. In the present analysis, the frequency of patients with any $\mathrm{AE}$ within each comorbidity subgroup was generally similar between those treated with ceftaroline fosamil and vancomycin plus aztreonam. 


\section{CONCLUSIONS}

In conclusion, this pooled analysis of three randomized controlled trials provides supportive evidence of the efficacy of ceftaroline fosamil in patients with cSSTI with underlying comorbidities.

\section{ACKNOWLEDGEMENTS}

The authors thank the patients, their families, and all investigators involved in the ceftaroline fosamil clinical trial program.

Funding. The CANVAS 1 and 2 trials were sponsored by Forest Laboratories, a subsidiary of AbbVie (following its acquisition of Allergan). The COVERS trial was originally sponsored by AstraZeneca and is now sponsored by Pfizer. AstraZeneca's rights to ceftaroline fosamil were acquired by Pfizer in December 2016. Ceftaroline fosamil is being developed by Pfizer and AbbVie (following its acquisition of Allergan). Funding for the journal's Rapid Service Fee was provided by Pfizer.

Medical Writing and/or Editorial Assistance. Medical writing support was provided by Melanie More of Prime, Knutsford, Cheshire, UK, funded by Pfizer. Ultimate responsibility for opinions, conclusions, and data interpretation lies with the authors.

Authorship. All named authors meet the International Committee of Medical Journal Editors (ICMJE) criteria for authorship for this article, take responsibility for the integrity of the work as a whole, and have given their approval for this version to be published.

Author Contributions. All authors were involved in either drafting or reviewing of the manuscript; MK and GGS designed the research; MD and MW performed the research; GGS, PLG, and JLY analyzed the data.

Disclosures. Jean Li Yan, Gregory G. Stone, and Michal Kantecki are employees of and shareholders in Pfizer. Pedro L. Gonzalez is a former employee of AbbVie, and is currently an employee of BD. Mark Wilcox and Matthew Dryden received institutional research funding for the conduct of studies included in these analyses from the respective study sponsors. Mark Wilcox has received consulting fees from AiCuris, AstraZeneca, Bayer, Cerexa, Durata, The Medicines Company, Menarini, Motif Biosciences, Nabriva, Paratek, and Pfizer; lecture fees from AbbVie, AstraZeneca, and Pfizer; and grant support from Motif Biosciences, Nabriva, Paratek, Pfizer, Qpex Biopharma, and VenatoRx.

Compliance with Ethics Guidelines. This pooled analysis was based on three previously reported phase III ceftaroline fosamil clinical trials. Ethics approval of the study protocols and any amendments from the relevant IRB/IECs and written informed consent were obtained for each trial $[1,8,9]$, and all trials were conducted in accordance with the Helsinki Declaration of 1964 and its later amendments.

Data Availability. Upon request, and subject to certain criteria, conditions and exceptions, see (https://www.pfizer.com/science/ clinical-trials/trial-data-and-results for more information), Pfizer will provide access to individual de-identified participant data from Pfizer-sponsored global interventional clinical studies conducted for medicines, vaccines and medical devices (1) for indications that have been approved in the US and/or EU or (2) in programs that have been terminated (i.e., development for all indications has been discontinued). Pfizer will also consider requests for the protocol, data dictionary, and statistical analysis plan. Data may be requested from Pfizer trials 24 months after study completion. The de-identified participant data will be made available to researchers whose proposals meet the research criteria and other conditions, and for which an exception does not apply, via a secure portal. To gain access, data requestors must enter into a data access agreement with Pfizer.

Open Access. This article is licensed under a Creative Commons Attribution- 
NonCommercial 4.0 International License, which permits any non-commercial use, sharing, adaptation, distribution and reproduction in any medium or format, as long as you give appropriate credit to the original author(s) and the source, provide a link to the Creative Commons licence, and indicate if changes were made. The images or other third party material in this article are included in the article's Creative Commons licence, unless indicated otherwise in a credit line to the material. If material is not included in the article's Creative Commons licence and your intended use is not permitted by statutory regulation or exceeds the permitted use, you will need to obtain permission directly from the copyright holder. To view a copy of this licence, visit http:// creativecommons.org/licenses/by-nc/4.0/.

\section{REFERENCES}

1. Corey GR, Wilcox MH, Talbot GH, Thye D, Friedland D, Baculik T. CANVAS 1: the first Phase III, randomized, double-blind study evaluating ceftaroline fosamil for the treatment of patients with complicated skin and skin structure infections. J Antimicrob Chemother. 2010;65(Suppl 4): iv41-51.

2. Esposito S, Bassetti M, Concia E, et al. Diagnosis and management of skin and soft-tissue infections (SSTI). A literature review and consensus statement: an update. J Chemother (Florence, Italy). 2017;29(4):197-214.

3. Zervos MJ, Freeman K, Vo L, et al. Epidemiology and outcomes of complicated skin and soft tissue infections in hospitalized patients. J Clin Microbiol. 2012;50(2):238-45.

4. Garau J, Ostermann H, Medina J, Avila M, McBride $\mathrm{K}$, Blasi F. Current management of patients hospitalized with complicated skin and soft tissue infections across Europe (2010-2011): assessment of clinical practice patterns and real-life effectiveness of antibiotics from the REACH study. Clin Microbiol Infect. 2013;19(9):E377-85.

5. Ki V, Rotstein C. Bacterial skin and soft tissue infections in adults: a review of their epidemiology, pathogenesis, diagnosis, treatment and site of care. Can J Infect Dis Med Microbiol. 2008;19(2):173-84.
6. Bassetti M, Baguneid M, Bouza E, Dryden M, Nathwani D, Wilcox M. European perspective and update on the management of complicated skin and soft tissue infections due to methicillin-resistant Staphylococcus aureus after more than 10 years of experience with linezolid. Clin Microbiol Infect. 2014;20(Suppl 4):3-18.

7. Stevens DL, Bisno AL, Chambers HF, et al. Practice guidelines for the diagnosis and management of skin and soft tissue infections: 2014 update by the Infectious Diseases Society of America. Clin Infect Dis. 2014;59(2):e10-52.

8. Wilcox MH, Corey GR, Talbot GH, Thye D, Friedland D, Baculik T. CANVAS 2: the second phase III, randomized, double-blind study evaluating ceftaroline fosamil for the treatment of patients with complicated skin and skin structure infections. J Antimicrob Chemother. 2010;65(suppl 4): iv53-65.

9. Dryden M, Zhang Y, Wilson D, Iaconis JP, Gonzalez J. A Phase III, randomized, controlled, non-inferiority trial of ceftaroline fosamil $600 \mathrm{mg}$ every $8 \mathrm{~h}$ versus vancomycin plus aztreonam in patients with complicated skin and soft tissue infection with systemic inflammatory response or underlying comorbidities. J Antimicrob Chemother. 2016;71(12):3575-84.

10. Matzneller P, Lackner E, Lagler H, Wulkersdorfer B, Österreicher Z, Zeitlinger M. Single- and repeateddose pharmacokinetics of ceftaroline in plasma and soft tissues of healthy volunteers for two different dosing regimens of ceftaroline fosamil. Antimicrob Agents Chemother. 2016;60(6):3617-25.

11. Corey GR, Wilcox MH, Gonzalez J, et al. Ceftaroline fosamil therapy in patients with acute bacterial skin and skin-structure infections with systemic inflammatory signs: a retrospective dose comparison across three pivotal trials. Int J Antimicrob Agents. 2019;53(6):830-7.

12. Miettinen $\mathrm{O}$, Nurminen $\mathrm{M}$. Comparative analysis of two rates. Stat Med. 1985;4(2):213-26.

13. Kofteridis DP, Valachis A, Koutsounaki E, et al. Skin and soft tissue infections in patients with solid tumours. Scientific World J. 2012;2012:804518.

14. Maroz N, Simman R. Wound healing in patients with impaired kidney function. J Am Coll Clin Wound Special. 2013;5(1):2-7.

15. Pinder M, Bellomo R, Lipman J. Pharmacological principles of antibiotic prescription in the critically ill. Anaesth Intensive Care. 2002;30(2):134-44.

16. Skhirtladze K, Hutschala D, Fleck T, et al. Impaired target site penetration of vancomycin in diabetic 
patients following cardiac surgery. Antimicrob Agents Chemother. 2006;50(4):1372-5.

17. Lipsky BA, Itani KM, Weigelt JA, et al. The role of diabetes mellitus in the treatment of skin and skin structure infections caused by methicillin-resistant Staphylococcus aureus: results from three randomized controlled trials. Int J Infect Dis. 2011;15(2):e140-6.

18. Eckmann C, Nathwani D, Lawson W, et al. Comparison of vancomycin and linezolid in patients with peripheral vascular disease and/or diabetes in an observational European study of complicated skin and soft-tissue infections due to methicillinresistant Staphylococcus aureus. Clin Microbiol Infect. 2015;21(Suppl 2):S33-9.

19. Pesanti EL. Immunologic defects and vaccination in patients with chronic renal failure. Infect Dis Clin N Am. 2001;15(3):813-32.

20. Tognetti L, Martinelli C, Berti S, et al. Bacterial skin and soft tissue infections: review of the epidemiology, microbiology, aetiopathogenesis and treatment: a collaboration between dermatologists and infectivologists. J Eur Acad Dermatol Venereol JEADV. 2012;26(8):931-41.

21. Bury D, ter Heine R, van de Garde EMW, Nijziel MR, Grouls RJ, Deenen MJ. The effect of neutropenia on the clinical pharmacokinetics of vancomycin in adults. Eur J Clin Pharmacol. 2019;75(7):921-8.

22. de Gatta MMF, Fruns I, Hernández JM, et al. Vancomycin pharmacokinetics and dosage requirements in hematologic malignancies. Clin Pharm. 1993;12(7):515-20.

23. Hochart C, Berthon C, Corm S, et al. Vancomycin serum concentration during febrile neutropenia in patients with acute myeloid leukemia. Med Mal Infect. 2011;41(12):652-6.

24. Theofiles M, Maxson J, Herges L, Marcelin A, Angstman KB. Cellulitis in obesity: adverse outcomes affected by increases in body mass index. J Prim Care Community Health. 2015;6(4):233-8.

25. Halilovic J, Heintz BH, Brown J. Risk factors for clinical failure in patients hospitalized with cellulitis and cutaneous abscess. J Infect. 2012;65(2): 128-34.

26. Falagas ME, Athanasoulia AP, Peppas G, Karageorgopoulos DE. Effect of body mass index on the outcome of infections: a systematic review. Obes Rev. 2009;10(3):280-9.

27. Longo C, Bartlett G, Macgibbon B, et al. The effect of obesity on antibiotic treatment failure: a historical cohort study. Pharmacoepidemiol Drug Saf. 2013;22(9):970-6.

28. Justo JA, Mayer SM, Pai MP, et al. Pharmacokinetics of ceftaroline in normal body weight and obese (classes I, II, and III) healthy adult subjects. Antimicrob Agents Chemother. 2015;59(7): 3956-65.

29. Ramakrishnan K, Salinas RC, Agudelo Higuita NI. Skin and soft tissue infections. Am Fam Physician. 2015;92(6):474-83.

30. Allergan. TEFLARO ${ }^{\mathrm{TM}}$ (ceftaroline fosamil) injection for intravenous (IV) use. 2020. https://www. allergan.com/assets/pdf/teflaro_pi. Accessed $28 \mathrm{Apr}$ 2021.

31. Pfizer. Zinforo $600 \mathrm{mg}$ powder for concentrate for solution for infusion: summary of product characteristics. 2020. https://www.ema.europa.eu/en/ documents/product-information/zinforo-eparproduct-information_en.pdf. Accessed 28 Apr 2021.

32. Cheng K, Newell P, Chow JW, et al. Safety profile of ceftazidime-avibactam: pooled data from the adult phase II and phase III clinical trial programme. Drug Saf. 2020;43(8):751-66. 